\title{
A study of hydrate plug formation in a subsea natural gas pipeline using a novel high-pressure flow loop
}

\author{
Li Wenqing ${ }^{1}$, Gong Jing ${ }^{1 *}$, Lü Xiaofang ${ }^{1}$, Zhao Jiankui ${ }^{2}$, Feng Yaorong ${ }^{3}$ and \\ Yu Da ${ }^{1}$ \\ ${ }^{1}$ Beijing Key Laboratory of Urban Oil and Gas Distribution Technology, China University of Petroleum, Beijing 102249, \\ China \\ ${ }^{2}$ China National Oil and Gas Exploration and Development Corporation, Beijing 100034, China \\ ${ }^{3}$ CNPC Tubular Goods Research Institute, Xi'an, Shaanxi 710065, China
}

(C) China University of Petroleum (Beijing) and Springer-Verlag Berlin Heidelberg 2013

\begin{abstract}
The natural gas pipeline from Platform QK18-1 in the southwest of Bohai Bay to the onshore processing facility is a subsea wet gas pipeline exposed to high pressure and low temperature for a long distance. Blockages in the pipeline occur occasionally. To maintain the natural gas flow in the pipeline, we proposed a method for analyzing blockages and ascribed them to the hydrate formation and agglomeration. A new high-pressure flow loop was developed to investigate hydrate plug formation and hydrate particle size, using a mixture of diesel oil, water, and natural gas as experimental fluids. The influences of pressure and initial flow rate were also studied. Experimental results indicated that when the flow rate was below $850 \mathrm{~kg} / \mathrm{h}$, gas hydrates would form and then plug the pipeline, even at a low water content $(10 \%)$ of a water/oil emulsion. Furthermore, some practical suggestions were made for daily management of the subsea pipeline.
\end{abstract}

Key words: Natural gas hydrate, blockage, flow assurance, high-pressure loop, water cut, flow rate

\section{Introduction}

As more and more oil and gas has been discovered and recovered from deep water and ultra deep-water fields, natural gas is transported in subsea pipelines at low temperature and high pressure. The low temperature and high pressure conditions may cause natural gas and water transported in the pipelines to form gas hydrates. Upon formation, hydrate accumulation and agglomeration eventually form a slug, blocking the flow in the pipelines. Therefore, more and more attention has been paid to developing flow assurance strategies to prevent hydrate plug formation (Andersson and Gudmundsson, 1999; 2006; Gaillard et al, 1999; Gudmundsson and Graff, 2003; Ning et al, 2007; Wang et al, 2007; Greaves et al, 2008; Dong et al, 2009; Balakin et al, 2010a; 2010b; 2010c). Unfortunately, little research is focused on the phenomena involved in a hydrate plug formation due to the strict requirements for experimental equipment and conditions, especially on an industrial scale. Since 2003, the Center for Hydrate Research at the Colorado School of Mines had been developing a hydrate formation model-CSMHyK (Turner et al, 2005a; 2005b), available as a

*Corresponding author. email: ydgj@cup.edu.cn

Received March 14, 2012 plug-in module for the oil \& gas analysis package (OLGA), to provide an estimate of where and approximately when a hydrate plug may form in collaboration with the SPT Group. Boxall et al (2008a) performed flow loop tests to verify the hydrate formation model and to investigate the effect of experimental variables on the plugging behavior of hydrate formation in water-in-oil emulsions. Davies et al (2010) developed a model to predict hydrate plug formation by studying the mass and heat transfer resistances to hydrate formation in oil-dominated systems, and the revised hydrate formation model had been validated on both laboratory and industrial scales. Emmanuel et al (2008) presented the effects of key variables on the plugging tendency of model fluids and crude oil systems by conducting tests in the flow assurance loop (FAL) of Tulsa under steady-state and stop-start conditions. Test results indicated that the plugging behavior of oil system is dependent on these variables and the oil-water chemical properties. Nevertheless, up to now there seldom has been systematic work relating experimental research into real plugging practices, and the results are also system dependent, making the reliability of those results to the actual conditions questionable. Therefore, it is necessary and meaningful to perform relevant studies based on real hydrate blockage incidents. In this paper, a typical blockage as below was studied by using a novel high-pressure flow loop. 
In the southwest of Bohai Bay, the subsea gas pipeline between the QK18-1 central platform and the onshore natural gas processing plant is about $48 \mathrm{~km}$ long. The main medium transported was wet gas containing light hydrocarbon and vapor, and the flow rate was about $9,500 \mathrm{Sm}^{3} / \mathrm{h}$. The operation temperature and pressure of the pipeline was 5-45 ${ }^{\circ} \mathrm{C}$, and 1.5-2.1 MPa, respectively. On 14th February 2011, there was something wrong in the pipeline between Platform QK18-1 and the Boxi processing plant. The inlet pressure reached as high as $2.8 \mathrm{MPa}$ (the normal inlet pressure was 2.1 $\mathrm{MPa}$ ), and the flow rate of the subsea pipeline dropped sharply. Through adjusting the inlet and outlet pressures and the injection of methanol both upstream and downstream, the gas transportation was barely maintained. However, the flow rate and the pressure fluctuated rapidly (the transient flow rate was $0-10,000 \mathrm{~m}^{3} / \mathrm{h}$ ), greatly influencing the normal gas transportation. Based on the analysis of the actual work conditions, it was inferred that three reasons may have led to the increased inlet pressure, which are listed as follows:

1) There were hydrate plugs in the subsea pipeline.

2) Liquids accumulated too much in the pipeline, and then the pressure drop along the pipeline increased.

3) A pig lost in the pipeline blocked the pipeline.

According to the records of pigging operation, there was no pig lost in the pipeline, but in the processing plant a great amount of liquid was discharged. In this paper, theoretical and experimental research is done to further investigate hydrate plug formation in gas transportation pipelines.

\section{Theoretical and experimental analyses of gas samples}

To determine phase distribution in the pipeline, three gas samples were taken at the inlet of the subsea gas pipeline on Platform QK18-1, and their compositions are listed in Table 1. The phase envelope of the gas mixture was obtained from the Peng-Robinson (PR) equation of state (Peng and Robinson, 1976) and four calculated values were verified from experimental data, as shown in Fig. 1. This indicated that the calculated results were in good agreement with experimental results. Therefore, the phase envelope may be used to predict the phase state of the gas mixture transported in the gas pipeline under various operating conditions. Due to the fact that the natural gas under pipeline operating conditions (temperature: $5-45{ }^{\circ} \mathrm{C}$, pressure: $1.5-2.1 \mathrm{MPa}$ ) was in the two-phase region, there may be liquid hydrocarbons in the pipeline, which was confirmed by the liquid sample observed in the pipeline. A sampling analysis (Fig. 2) showed that the liquid contained gas condensates and free water, which was similar to the problem encountered in the West-East Gas Pipeline described in 2005 (Zhao et al, 2009).

Free water was found in the accumulated liquid samples, so the gas (methane) in the pipeline might combine with water to form hydrates under specific thermodynamic conditions. In our laboratory, a sapphire autoclave was used to investigate whether the reaction occurred and hydrate formation conditions were measured using an isothermal pressure search method.

The two-step hydrate formation mechanism proposed
Table 1 The composition of gas samples

$(\mathrm{mol} \%)$

\begin{tabular}{ccccc}
\hline \multirow{2}{*}{ Component } & \multicolumn{3}{c}{ Sample } & Average \\
\cline { 2 - 4 } & $\mathrm{S} 1$ & $\mathrm{~S} 2$ & $\mathrm{~S} 3$ & \\
\hline $\mathrm{C}_{1}$ & 87.1 & 86.6 & 87.0 & 86.9 \\
$\mathrm{C}_{2}$ & 6.06 & 5.86 & 6.09 & 6.00 \\
$\mathrm{C}_{3}$ & 3.23 & 3.20 & 3.36 & 3.26 \\
$i-\mathrm{C}_{4}$ & 0.634 & 0.644 & 0.655 & 0.644 \\
$n-\mathrm{C}_{4}$ & 1.11 & 1.12 & 1.15 & 1.13 \\
$i-\mathrm{C}_{5}$ & 0.33 & 0.277 & 0.343 & 0.317 \\
$n-\mathrm{C}_{5}$ & 0.249 & 0.256 & 0.217 & 0.241 \\
$\mathrm{C}_{6+}$ & 0.264 & 0.37 & 0.315 & 0.316 \\
$\mathrm{CO}_{2}$ & 0.716 & 0.653 & 0.735 & 0.705 \\
$\mathrm{~N}_{2}$ & 0.307 & 1.02 & 0.135 & 0.487 \\
\hline $\mathrm{Sum}$ & 100 & 100 & 100 & 100 \\
\hline
\end{tabular}

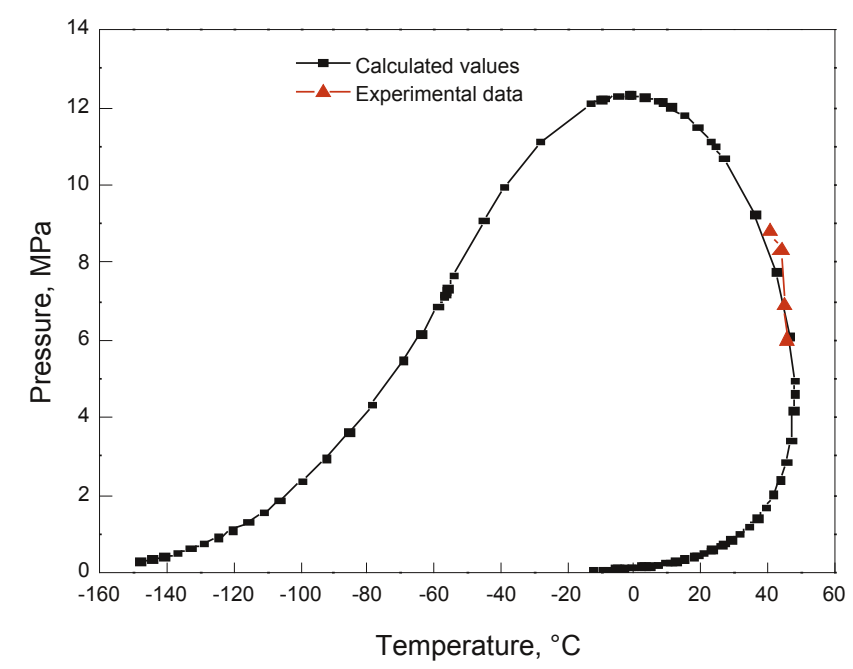

Fig. 1 Phase envelope of the gas sample taken from the subsea pipeline

by Chen and Guo for gas hydrate formation was adopted as the conceptual picture. The first step is the formation of a stoichiometric basic hydrate through a quasi-chemical reaction and the second step is the adsorption of gas molecules into empty linked cavities of the basic hydrate. The natural gas hydrate formation curve was predicted by the Chen-Guo model (Chen and Guo, 1996; 1998).

Fig. 3 showed that the simulation results were in good agreement with experimental values. This model could be used to predict formation conditions of hydrates in the subsea gas pipeline. By using commercial software PIPESIM, the pressure and temperature values along the pipeline were simulated. Then, the hydrate formation pressure values at simulated temperatures of each pipeline section were calculated from the Chen-Guo model, as shown in Fig. 4. The results indicated that most of the simulated pressures were above the hydrate formation pressure. So if any free water existed in the pipeline, gas hydrates would be formed. Therefore, it was reasonable to ascribe the cause of this incident to hydrate blockage in the pipeline. 


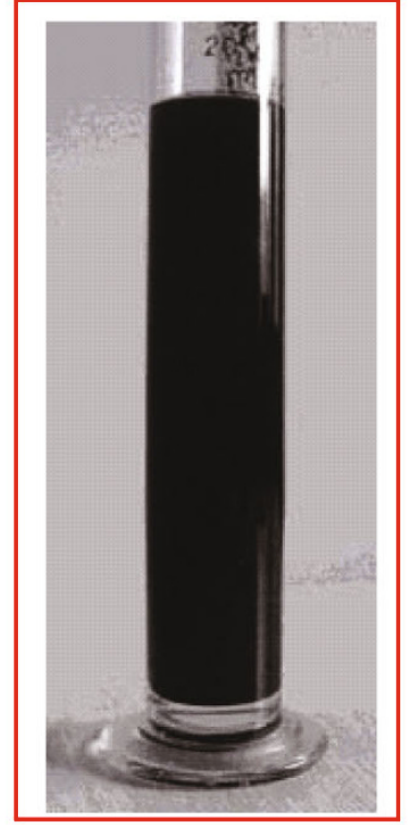

(a) Sediment/condensate/suspension

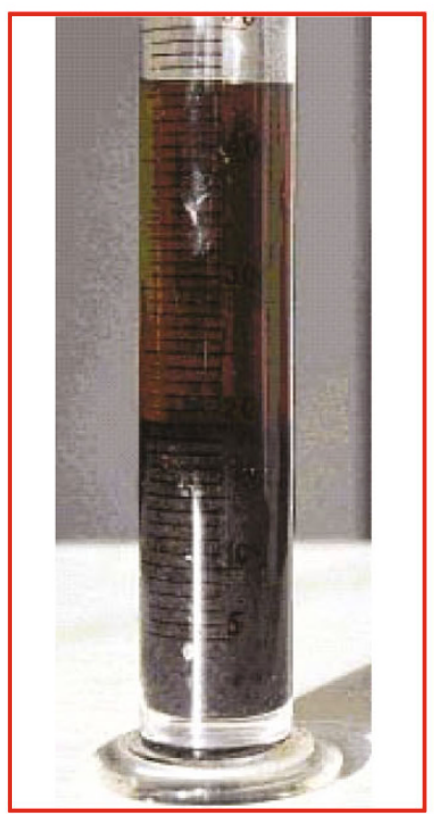

(b) Sediment/condensate/suspension after standing for 24 hours

Fig. 2 Images of the sediment/condensate/suspension taken from the natural gas pipeline

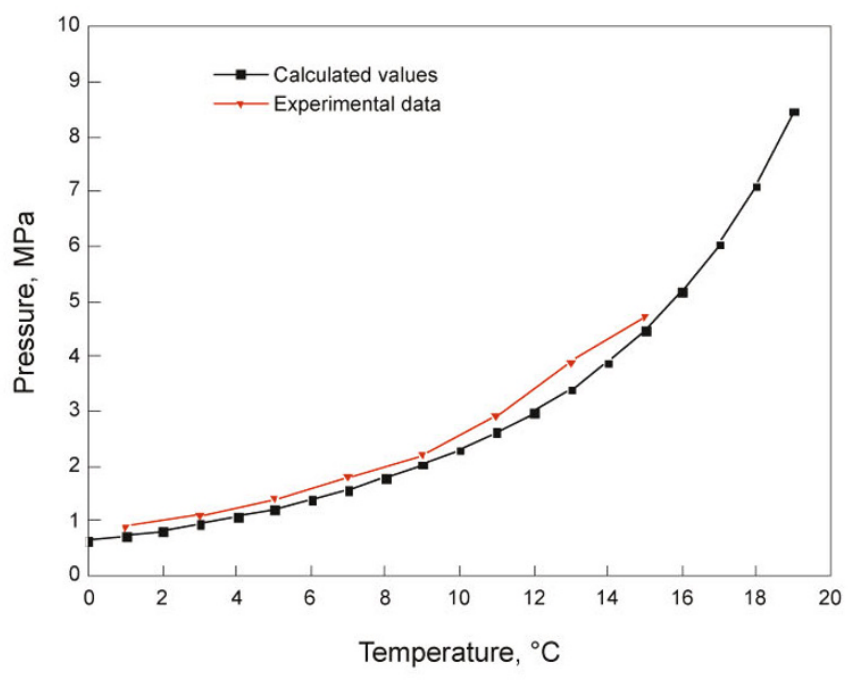

Fig. 3 Hydrate formation curves of a gas sample in the subsea pipeline

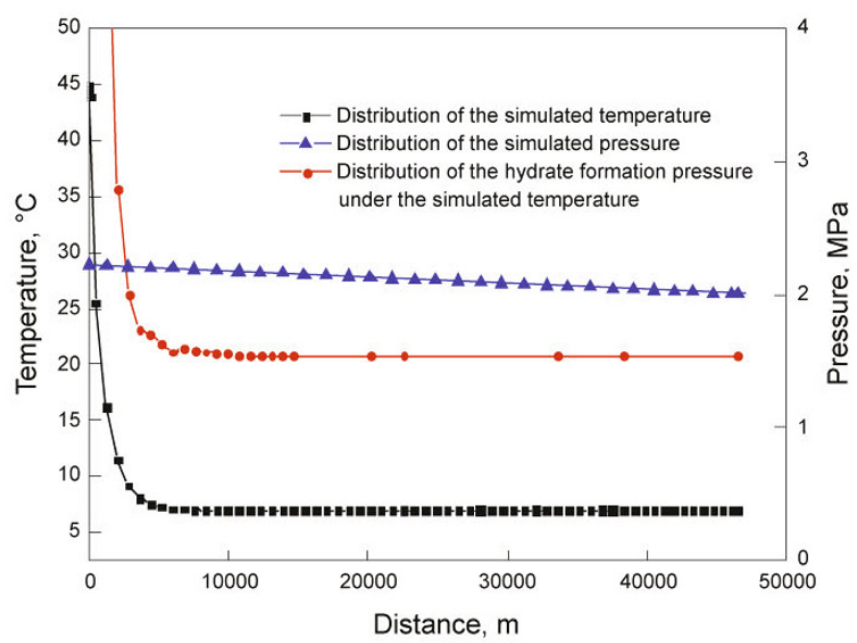

Fig. 4 Prediction for the hydrate formation region in the subsea pipeline

\section{Experimental research on hydrate plug formation in the pipeline}

\subsection{High pressure flow loop for hydrate formation}

A hydrate flow loop was built in China University of Petroleum (Beijing) to investigate gas hydrate formation and flow behavior in gas pipelines. This flow loop allowed a mixture of gas and liquids at high pressures to be circulated within a stainless steel flow line and could be used to simulate hydrate slurry under different deep-water conditions. A simplified layout of the flow loop is shown in Fig. 5.

The horizontal flow line was $2.51 \mathrm{~cm}$ in internal diameter, $30 \mathrm{~m}$ long, covered with a double jacket to limit the energy loss and to allow counter current flow of the cooling fluid. The loop could be pressurized up to $15 \mathrm{MPa}$ using a set of high-pressure gas cylinders and the temperature could be controlled from -20 to $80^{\circ} \mathrm{C}$ by means of a chiller unit circulating liquid coolant through a double jacket. The liquids (water and diesel oil) were circulated by a custom-made magnetic centrifugal pump (flow rate up to $12 \mathrm{~m}^{3} / \mathrm{h}$ ). At the outlet of the flow line, the fluids were collected into a $0.22 \mathrm{~m}^{3}$ insulated gas/liquid separator. To keep a constant pressure, gas was added to the loop from a set of gas cylinders for hydrate formation, and a mass flow meter and a depressuring valve were installed between the separator and the gas cylinders. The fluid inside the loop was visually inspected through high-pressure visualization windows at two different locations on the loop. In addition, the horizontal test part of the loop was placed in an air-conditioned room.

Focused beam reflectance measurement (FBRM) probe (Lasentec $($ ) $)$, the most advanced real-time particle size analysis technique, allows the in-situ measurement of distribution of the chord length of particles and the particle count number. The FBRM probe was installed in the loop. 


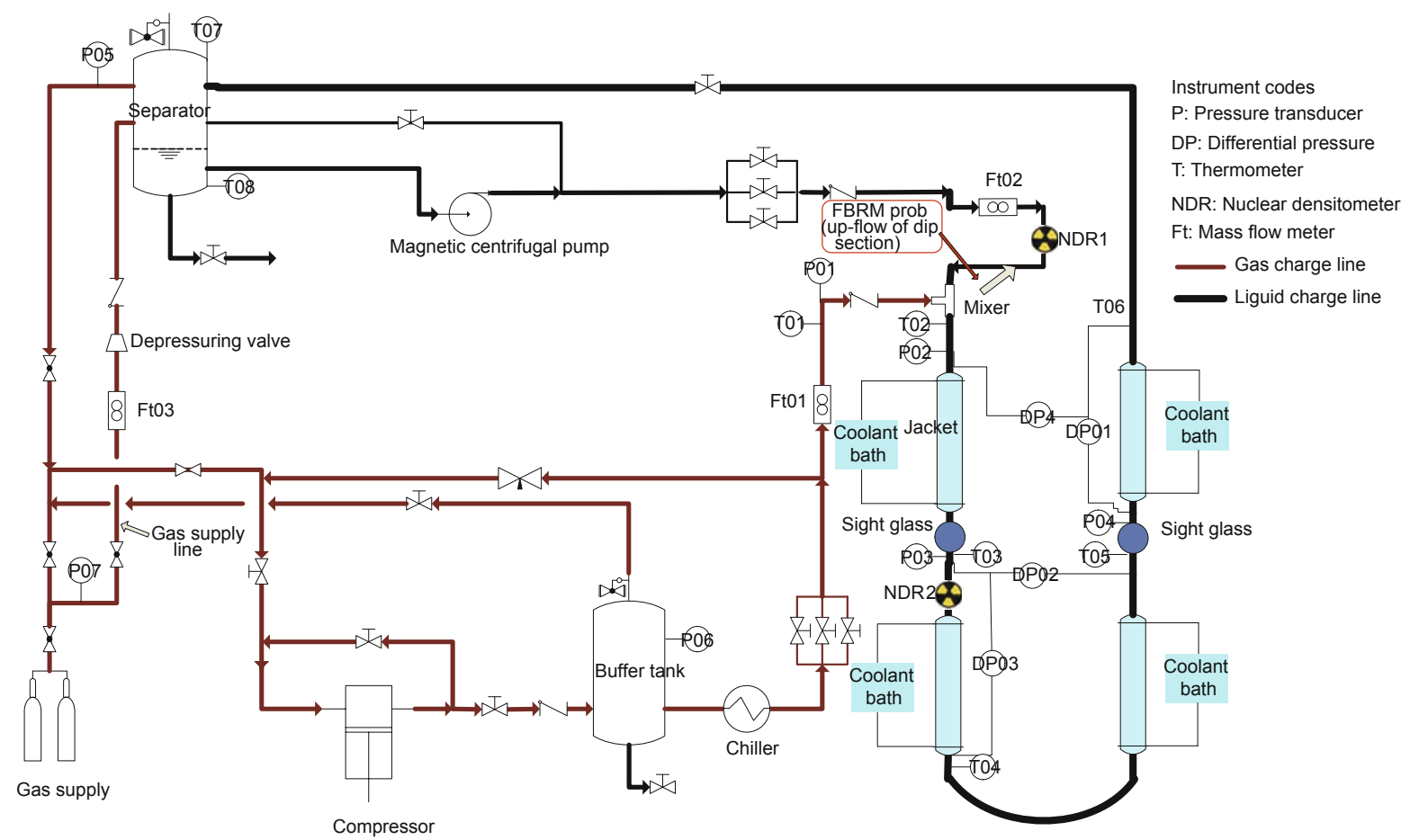

Fig. 5 Schematic of the high pressure hydrate flow loop (supported by CNOOC Research Institute in 2011)

It provided online monitoring of the evolution of objects (droplets, bubbles and solid particles) transporting inside the flow. The measure principle of the equipment had been described elsewhere (Pauchard et al, 2007; Boxall et al, 2008b; Darbouret et al, 2008). As recommended for a representative sampling of the particle size distribution, this particle size analyzer was installed in a straight vertical pipe, which was ahead of the inlet of the test loop. The window of the probe cut the flow streamlines at an angle of $45^{\circ}$ and reached the centre of the pipe. The FBRM probe was used to estimate the initial water droplet $\left(D_{\mathrm{p}}\right)$ size inside the fluid and to follow the hydrate particle agglomeration with time. The mean square-weighted chord length could give more weight to longer chord length and it was particularly well adapted to agglomeration phenomena.

\subsection{Fluids}

Deionized water, -20\# diesel oil and natural gas from the city network were used to simulate the mixture flowing in gas pipelines in all tests. The dry gas composition is listed in Table 2. The total volume of the liquid mixture (including water and diesel oil) flowing in the loop was $0.078 \mathrm{~m}^{3}$, with a $10 \%$ water content. The hydrate formation curve obtained from the Chen-Guo model is shown in Fig. 6.

\subsection{Experimental procedures}

To simulate the practical fluid flow in the subsea pipeline as much as possible, hydrate formation and plug formation tests were performed at a constant pumping speed and a constant static pressure. The experimental procedures are as follows.

1) A total of $0.078 \mathrm{~m}^{3}$ liquid mixture with a $10 \%$ water content was injected into the separator. The flow loop

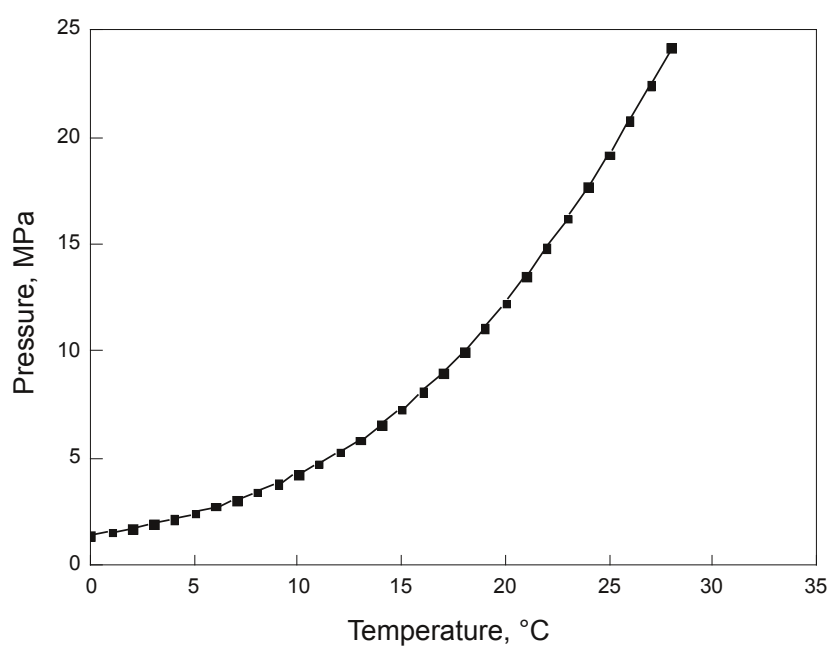

Fig. 6 Hydrate formation curve for the city natural gas

was then pressurized to $3.2 \mathrm{MPa}$ and the temperature was controlled at $18{ }^{\circ} \mathrm{C}$. The mixture was then saturated with natural gas under these conditions.

2) The gas-saturated water/oil mixture was circulated at a constant flow rate $(1,684 \mathrm{~kg} / \mathrm{h})$ to form a homogeneous and stabilized emulsion.

3) Under constant pressure and constant flow rate $(850$ $\mathrm{kg} / \mathrm{h}$ ), the temperature was decreased at a constant rate after setting the coolant bath temperature to $1{ }^{\circ} \mathrm{C}$. During the cooling-down period, gas was forced into the separator from the gas cylinders to maintain the system pressure at 3.2 $\mathrm{MPa}$.

4) In the hydrate formation process, the temperature, pressure, flow rate, density, and chord lengths were measured and recorded in real time. In this study, P05 and T05, shown in Fig. 5, were chosen as the pressure and temperature points 
Table 2 Natural gas composition used in all tests

\begin{tabular}{cc}
\hline Component & Composition, mol\% \\
\hline $\mathrm{N}_{2}$ & 1.56 \\
$\mathrm{CO}$ & 2.09 \\
$\mathrm{CO}_{2}$ & 0.913 \\
$\mathrm{C}_{1}$ & 90.6 \\
$\mathrm{C}_{2}$ & 3.12 \\
$\mathrm{C}_{3}$ & 1.33 \\
$\mathrm{C}_{4}$ & 0.329 \\
$\mathrm{C}_{5}$ & 0.0425 \\
$\mathrm{C}_{6+}$ & 0.0155 \\
\hline
\end{tabular}

to be analyzed, and the mass flow meter FT02 measured both mass flow rate and density.

5) When a hydrate blockage occurred, the flow rate was increased step by step to test the mixture transportability.

6) The hydrate dissociation was carried out by increasing the temperature to $18{ }^{\circ} \mathrm{C}$ and then the system was kept in these conditions $\left(18^{\circ} \mathrm{C}, 3.2 \mathrm{MPa}\right.$ (and 4.1 MPa)) for 12 hours.

7) The tests were repeated at different pressures and initial flow rates.

\section{Results and discussion}

\subsection{Influence of pressure}

The impact of pressure on hydrate formation was investigated at an initial flow rate of $850 \mathrm{~kg} / \mathrm{h}$. Figs. 7 and 8 indicate the temperature, density and flow rate varying with time at 3.2 and $4.1 \mathrm{MPa}$, respectively.

Fig. 7 indicated that the temperature decreased to $7.4{ }^{\circ} \mathrm{C}$, the equilibrium temperature for hydrate formation $\left(T_{\mathrm{e}}\right)$, then to $4.4{ }^{\circ} \mathrm{C}$, the hydrate formation temperature $\left(T_{\mathrm{f}}\right)$ and 2.9 ${ }^{\circ} \mathrm{C}$, the hydrate blockage temperature $\left(T_{\mathrm{b}}\right)$. The temperature cooling rate reduced from $T_{\mathrm{e}}$ to $T_{\mathrm{f}}$ and the temperature was kept nearly constant from $T_{\mathrm{f}}$ to $T_{\mathrm{b}}$. During the period from $T_{\mathrm{f}}$ to $T_{\mathrm{b}}$ the flow rate and the fluid density decreased sharply with time initially, and then slowly. This is because a great deal of heat was released due to the crystallization of hydrate particles when hydrates began to be formed, which led to a significant increase in fluid viscosity and fluid volume expansion. With more and more hydrates were formed, the hydrate formation rate would gradually reduce and be nearly constant in the end, so the rate of decrease of the flow rate and fluid density became small, and the occurrence of blockage was a result of hydrate generation, accumulation, agglomeration and finally plugging. After point $T_{\mathrm{b}}$, the flow rate reduced drastically and dropped rapidly to 0 , but the flow transportability could be restored by increasing the pump speed.

The duration from $T_{\mathrm{e}}$ to $T_{\mathrm{f}}$ was defined as the induction time $t_{\text {in }}$, the degree of super-cooling $\left(T_{\mathrm{c}}\right)$ was defined as the difference between the temperature that hydrate formation was first observed $\left(T_{\mathrm{f}}\right)$ and the equilibrium temperature $T_{\mathrm{e}}$ (Skovoborg et al, 1993; Natarajan et al, 1994; Sun et al,
$2004)$, and the blockage time $\left(t_{\mathrm{b}}\right)$ defined as the period from the test beginning to point $T_{\mathrm{b}}$ was about $11.4 \mathrm{~h}$.

Similar results were exhibited in Fig. 8, but the density curve after point $T_{\mathrm{f}}$ was found to be different from that obtained at a low pressure of 3.2 MPa. Higher pressure (4.1 $\mathrm{MPa}$ ) could increase the hydrate formation rate and promote aggregation of hydrate particles. Due to fast formation of aggregation, some gas bubbles were quickly sealed in them, resulting in an increase in the fluid volume and a reduction in the density. However, when the fluid passed the pump, the shear stress applied by the pump would break the agglomeration up and release gas, making the fluid volume reduce, and thereby increase its density. This was the reason why the value of the density in Fig. 8 first went down after the onset of hydrate formation and then increased. A comparison of corresponding parameters of two tests was also listed in Table 3 .

The time required for hydrate plug formation was related to pressure. The hydrate formation temperature $T_{\mathrm{f}}$ and blockage temperature $T_{\mathrm{b}}$ increased with pressure, but their corresponding durations decreased with pressure, so hydrate plugs were more easily formed at higher pipeline operating pressures.

Table 3 Comparisons of $T_{\mathrm{e}}, T_{\mathrm{f}}, T_{\mathrm{c}}$ and $T_{\mathrm{b}}$ at different pressures and initial flow rates

\begin{tabular}{ccccccccc}
\hline $\begin{array}{c}\text { Pressure } \\
\mathrm{MPa}\end{array}$ & $\begin{array}{c}\text { Initial flow rate } \\
\mathrm{kg} / \mathrm{h}\end{array}$ & $\begin{array}{c}T_{\mathrm{e}} \\
{ }^{\circ} \mathrm{C}\end{array}$ & $\begin{array}{c}t_{\mathrm{e}} \\
\mathrm{h}\end{array}$ & $\begin{array}{c}T_{\mathrm{f}} \\
{ }^{\circ} \mathrm{C}\end{array}$ & $\begin{array}{c}t_{\mathrm{f}} \\
\mathrm{h}\end{array}$ & $\begin{array}{c}T_{\mathrm{c}} \\
{ }^{\circ} \mathrm{C}\end{array}$ & $\begin{array}{c}T_{\mathrm{b}} \\
{ }^{\circ} \mathrm{C}\end{array}$ & $\begin{array}{c}t_{\mathrm{b}} \\
\mathrm{h}\end{array}$ \\
\hline 3.2 & 850 & 7.4 & 1.06 & 4.4 & 2.43 & 3.0 & 2.9 & 11.4 \\
4.1 & 850 & 9.5 & 0.78 & 6.3 & 1.47 & 3.2 & 3.5 & 5.63 \\
4.1 & 1940 & 9.5 & 0.65 & 6.5 & 1.86 & 3.0 & - & - \\
\hline
\end{tabular}

\subsection{Influence of initial flow rate}

After a hydrate plug was formed and started blocking the flow line, the flow rate was gradually raised to measure the transportability of the hydrate fluid at high flow rates. Figs. 7 and 8 indicated that the higher the initial flow rate, the easier the transportation of the fluid, and if the initial flow rate was high enough, the hydrate fluid would have a good transportability even a large amount of hydrates were formed. So a test was conducted at $4.1 \mathrm{MPa}$ and an initial flow rate of $1,940 \mathrm{~kg} / \mathrm{h}$, and the results were shown in Fig. 9. It could be seen that the trend of variation of temperature was similar to the above-mentioned at $850 \mathrm{~kg} / \mathrm{h}$, while the flow rate was different. With time, the flow rate also first reduced sharply, when down to $1,450 \mathrm{~kg} / \mathrm{h}$, it stopped decreasing. 40 minutes later, the flow rate began to increase quickly and finally plateaued at a value of $888 \mathrm{~kg} / \mathrm{h}$, lower than the initial flow rate. Moreover a blockage did not occur. Although the hydrate crystals began to form and agglomerate at the beginning, the high flow rate with strong carrying capability and shear stress could remove the hydrates deposited on the pipe wall and break the hydrate agglomerates up after a while to inhibit their further deposition and aggregation, and finally the flow was restored and maintained.

Corresponding parameters were also listed in Table 3. This indicated that the hydrate formation time $t_{\mathrm{f}}$ and blockage 


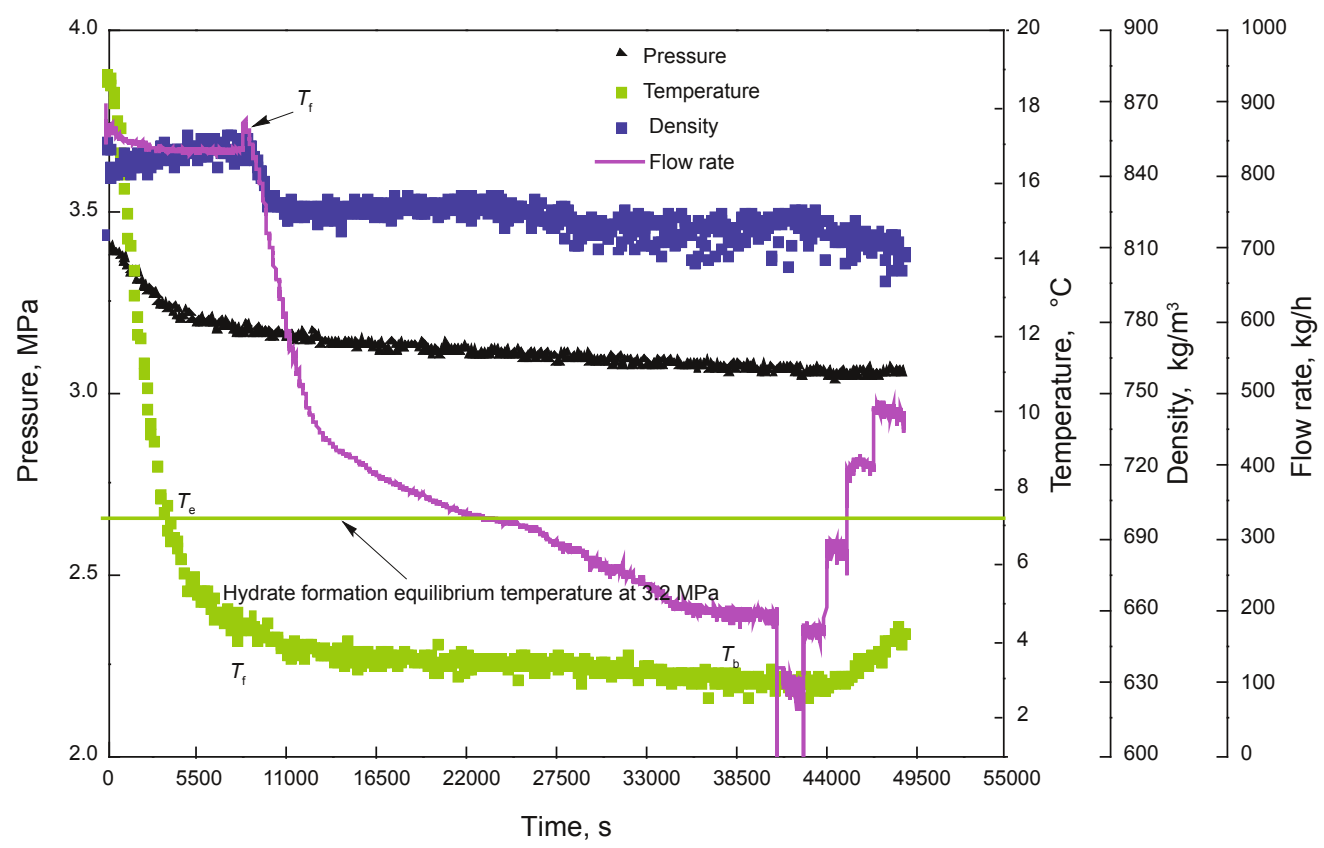

Fig. 7 Pressure, density, temperature and flow rate as functions of time during natural hydrate formation (initial flow rate $850 \mathrm{~kg} / \mathrm{h}, 3.2 \mathrm{MPa}, 10 \%$ water content)

time $t_{\mathrm{b}}$ were affected by the initial flow rate in the loop. The time required for hydrate formation and blockage increased with the initial flow rate, and if the flow rate was high enough $(1,940 \mathrm{~kg} / \mathrm{h})$ or even higher, no hydrate blockage occurred in the loop.

\subsection{The analysis of hydrate particle dimensions and blockage in pipe}

Thanks to the real time in-situ FBRM, the variety of crystals size of every test had been recorded. As shown in Fig. 10, the statistical chord length distributions of hydrate particles were similar at different times, and the dimensions of most hydrate particles were about $10 \mu \mathrm{m}$, a valuable reference for some calculation models. The mean square weighted chord length was measured and used to analyze the microscopic change of hydrate particles because its value was sensitive to large size particles. Fig. 11 showed the mean square-weighted chord length measured on the waterin-oil emulsion, in which two peaks could be observed, corresponding to the hydrate formation and blockage occurrence in Fig. 8. This suggested that when the hydrates began to be formed, crystal particles could agglomerate, and

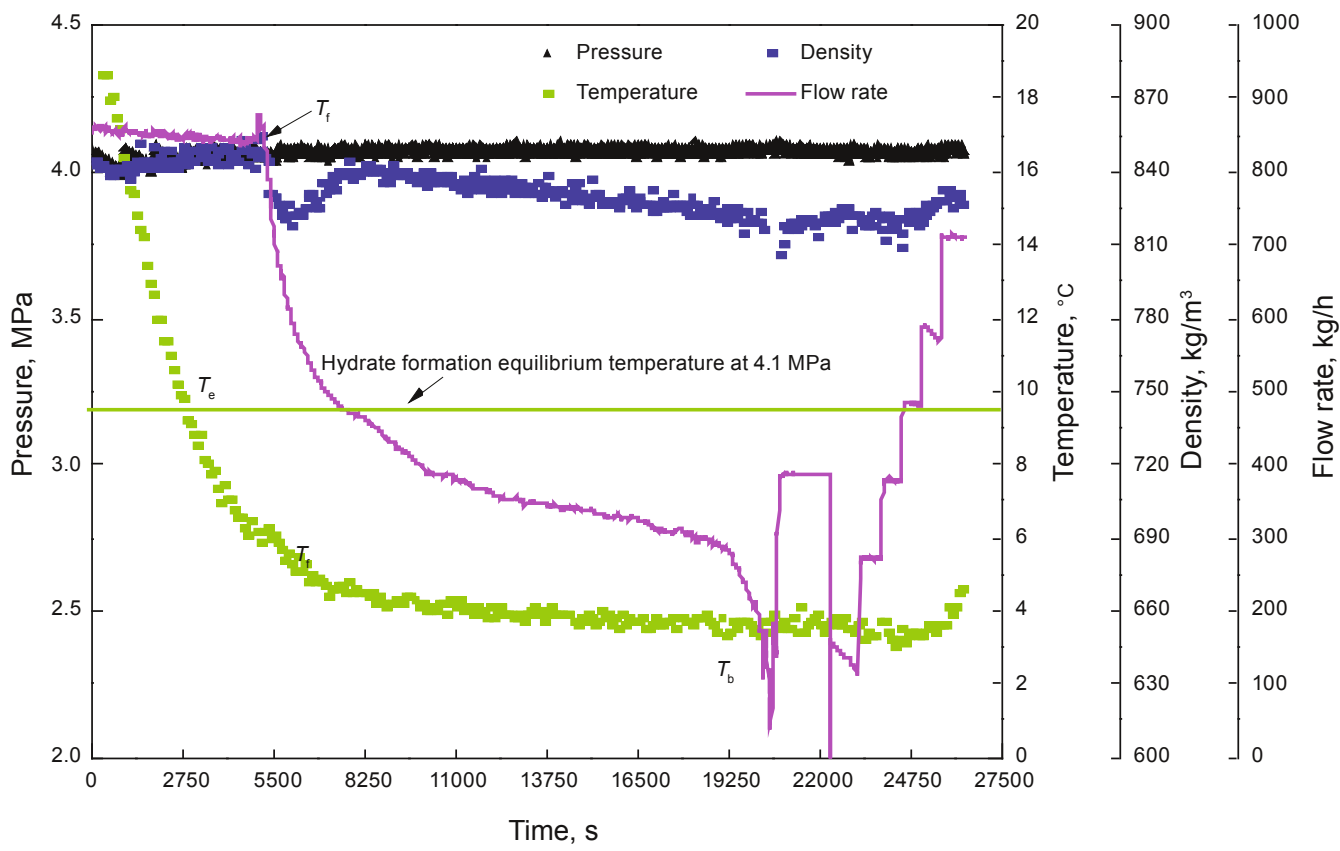

Fig. 8 Pressure, density, temperature and flow rate as functions of time during natural hydrate formation (initial flow rate $850 \mathrm{~kg} / \mathrm{h}, 4.1 \mathrm{MPa}, 10 \%$ water content) 


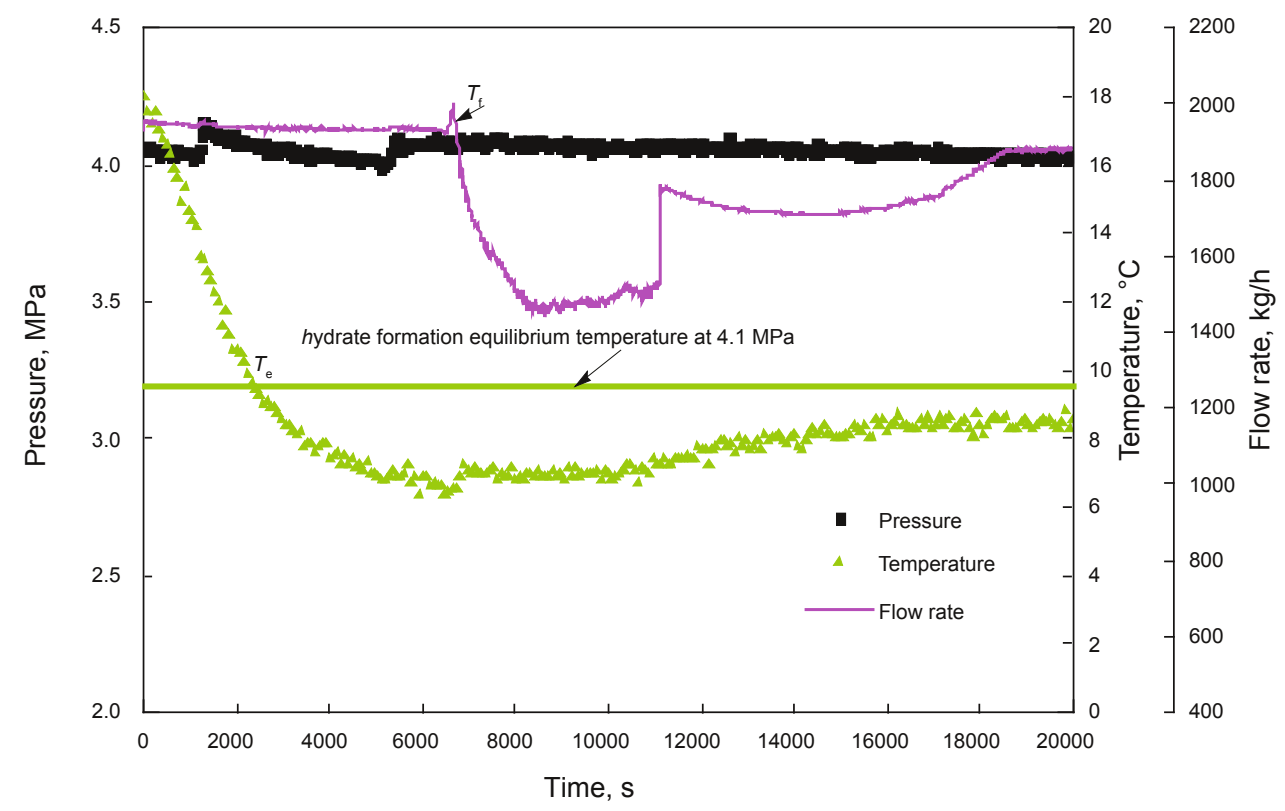

Fig. 9 Pressure, temperature and flow rate as functions of relative time during natural hydrate formation (initial flow rate $1,940 \mathrm{~kg} / \mathrm{h}, 4.1 \mathrm{MPa}, 10 \%$ water cut)

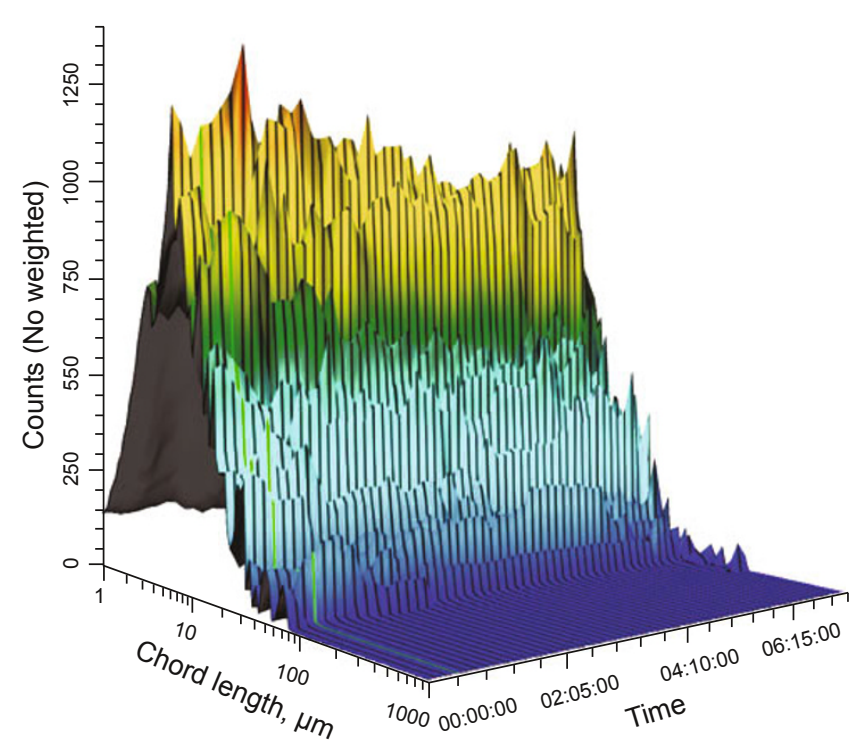

Fig. $103 \mathrm{D}$ diagram of un-weighted chord length distribution of hydrate particles during the test (initial flow rate $850 \mathrm{~kg} / \mathrm{h}, 4.1 \mathrm{MPa}$ )

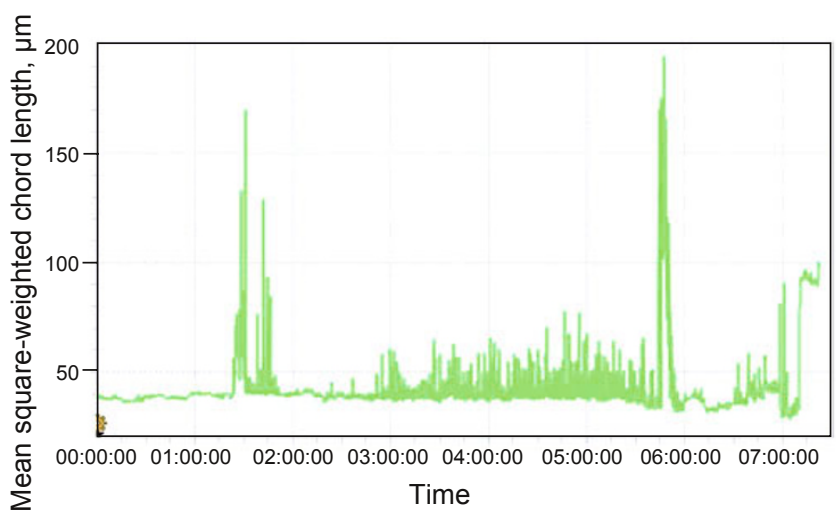

Fig. 11 Mean square-weighted chord length measured during the flow loop test (initial flow rate $850 \mathrm{~kg} / \mathrm{h}, 4.1 \mathrm{MPa}$ ) the mean square weighted chord length of the particles was about $170 \mu \mathrm{m}$. After experiencing shear stress exerted by the fluid flow and pump blade, the agglomerates were broken up and became smaller-size particles, but the hydrate crystals were also dispersed in the fluids, which increased the fluid viscosity and reduced the flow rate. With the decreased flow rate, the shear strength exerted by fluid flow and particlecarrying capability became weaker, and more and more hydrate particles agglomerated and accumulated on the pipe wall, where the fluid flow rate could be reduced most, forming a hydrate layer. With continued hydrate formation, agglomeration and deposition, the flow passage decreased gradually with the increasing thickness of the hydrate layer around the pipe wall until it was finally blocked. This was the reason why the mean square-weighted chord length reduced after the first peak, then increased gradually later, and reached the second peak $(195 \mu \mathrm{m})$ higher than the first peak. Photographs taken from the high-pressure visualization window at three different stages (before hydrate formation, hydrate formation and blockage occurrence) shown in Fig. 12 could also verify the above-mentioned. Due to the concave surface of the window inside the pipe, it could also be inferred from Fig. 12 that blockage occurred easily at concave, uneven surface and bent pipe section, where the flow rate reduced sharply. It may weaken the solid-carrying capability of fluids and cause more and more hydrate particles to aggregate, deposit and adhere on the pipe wall, and finally block the pipe.

\section{Conclusions and suggestions}

1) Reducing pressure and/or raising temperature could promote dissociation of hydrate crystals. However, it was impossible to heat the whole subsea pipeline. Decompressing the pipeline at its outlet could be a reasonable solution. Moreover, once the pipe was blocked, increasing the 


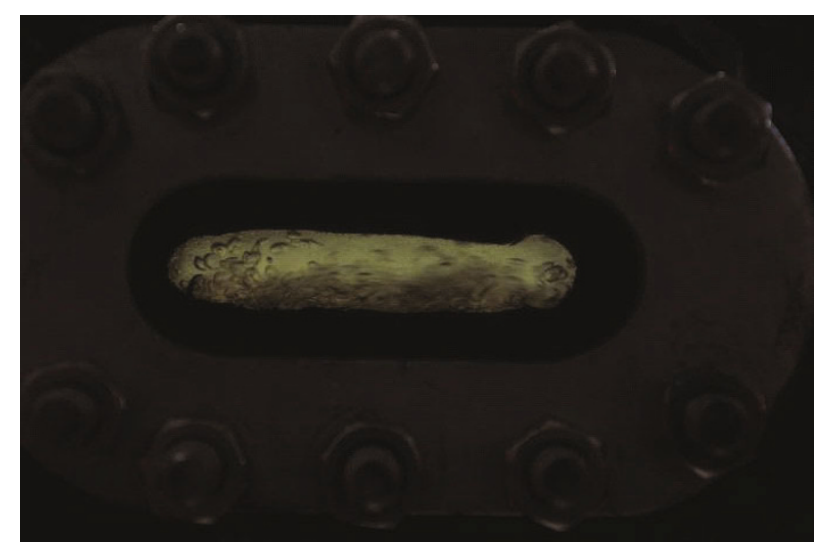

(a) Before hydrate formation

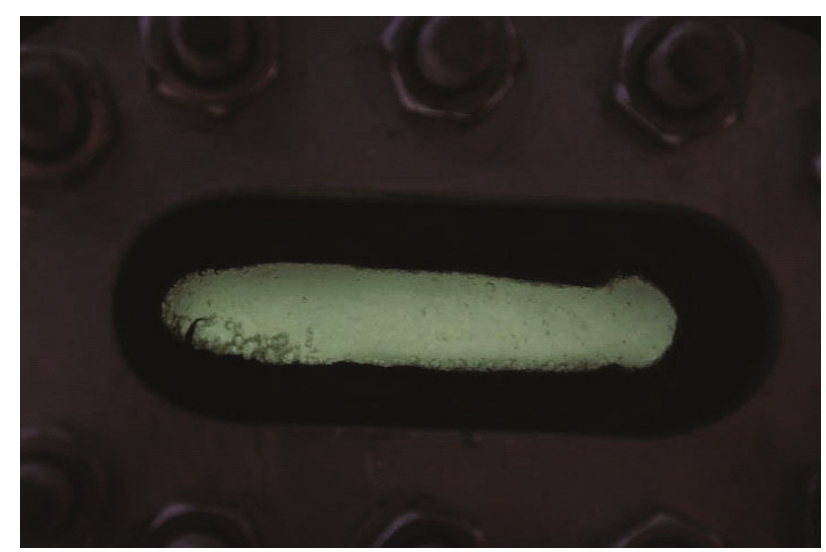

(b) Hydrate formation

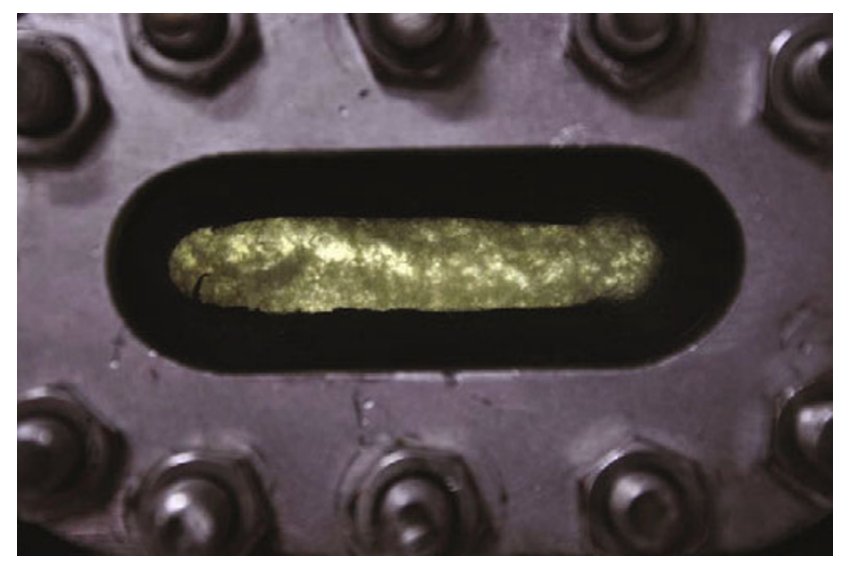

(c) Hydrate plug formation

Fig. 12 Photographs of three stages during the flow loop test (initial flow rate $850 \mathrm{~kg} / \mathrm{h}, 4.1 \mathrm{MPa}$ )

inlet pressure may even make the problem more serious. Meanwhile, pigging operations are also not recommended as these may accumulate and compact the sedimenting hydrates, leading to a more serious pipeline blockage.

2) If the flow rate was low enough, accumulative fluids with a low water content of $10 \%$ may have a risk of hydrate blockage in a wet natural gas pipeline. The methods used to reduce hydrate formation were to perform necessary pigging operation and regular shutoff pressure, and then to release pressure at the downstream (processing plant) in daily management, which could take the accumulated fluids out of the pipeline to eliminate or reduce the amount of free water to prevent hydrate formation. Particular attention should be paid to the operation of pressure relief, and the velocity and extent of releasing pressure should be controlled in accordance with the operating regulations to prevent unexpected hydrate formation due to low temperatures caused by throttle effect. Moreover, it was a better choice to perform dehydration treatment before gas transportation. These methods mentioned above had been carried out and ensured gas successfully passing through the pipeline section where gas hydrates are easily formed.

3) Adding chemical additives, especially kinetic hydrate inhibitors (KHI), at the inlet of the pipeline may be a promising solution to preventing hydrate formation in the hazardous areas.

\section{Acknowledgements}

The authors are grateful for financial support from Subtopics of National Science and Technology Major Project (2011ZX05026-004-03) and the National Natural Science Foundation of China (51104167).

\section{References}

Andersson V and Gudmundsson J S. Flow experiments on concentrated hydrate slurries. SPE Annual Technical Conference and Exhibition, Houston, Texas, USA, October 3-6, 1999

Andersson V and Gudmundsson J S. Flow properties of hydrate-in-water slurries. Annals of the New York Academy of Sciences. 2006. 912: 322-329

Balakin B V, Hoffmann A C and Kosinski P. Experimental study and computational fluid dynamics modeling of deposition of hydrate particles in a pipeline with turbulent water flow. Chemical Engineering Science. 2010a. 66(4): 755-765

Balakin B V, Hoffmann A C, Kosinski P, et al. Turbulent flow of hydrates in a pipeline of complex configuration. Chemical Engineering Science. 2010b. 65(17): 5007-5017

Balakin B V, Pedersen H, Kilinc Z, et al. Turbulent flow of R11 hydrate slurry. Journal of Petroleum Science and Engineering. 2010c. 70(34): $177-182$

Boxall J A, Davies S R, Nicholas J W, et al. Hydrate blockage potential in an oil-dominated system studied using a four inch flow loop. Proceedings of the 6th International Conference on Gas Hydrate, Vancouver, British Columbia, Canada, July 6-10, 2008a

Boxall J A, Greaves D P, Mulligan J, et al. Gas hydrate formation and dissociation from water-in-oil emulsions studied using PVM and FBRM particle size analysis. Proceedings of the 6th International Conference on Gas Hydrate, Vancouver, British Columbia, Canada, July 6-10, 2008b

Chen G J and Guo T M. Thermodynamic modeling of hydrate formation based on new concepts. Fluid Phase Equilib. 1996. 112(1-2): 43-65

Chen G J and Guo T M. A new approach to gas hydrate modeling. Chemical Engineering Journal. 1998. 71: 145-151

Darbouret M, Ba H L, Cameirao A, et al. Lab scale and pilot scale comparison of crystallization of hydrate slurries from a water-inoil emulsion using chord length measurements. Proceedings of the 6th International Conference on Gas Hydrate, Vancouver, British Columbia, Canada, July 6-10, 2008

Davies S R, Boxall J A, Dieker L E, et al. Predicting hydrate plug formation in oil-dominated flowlines. Journal of Petroleum Science and Engineering. 2010. 72(3-4): 302-309

Dong T B, Wang L Y, Liu A X, et al. Experimental study of separation of ammonia synthesis vent gas by hydrate formation. Petroleum 
Science. 2009. 6(2): 188-193

Emmanuel D, Giorgio G, Lissett B, et al. Hydrate plugging or slurry flow: Effect of key variables. Proceedings of the 6th International Conference on Gas Hydrate, Vancouver, British Columbia, Canada, July 6-10, 2008

Gaillard C, Monfort J P and Peytavy J L. Investigation of methane hydrate formation in a recirculating flow loop: Modeling of the kinetics and tests of efficiency of chemical additives on hydrate inhibition. Oil \& Gas Science and Technology. 1999. 54(3): 365-374

Greaves D, Boxall J and Mulligan J. Hydrate formation from high water content-crude oil emulsions. Chemical Engineering Science. 2008. 63: 4570-4579

Gudmundsson J S and Graff O F. Hydrate non-pipeline technology for transport of natural gas. 22th World Gas Conference, Tokyo, Japan, June 1-5, 2003

Natarajan V, Bishnoi P R and Kalogerakis N. Induction phenomena in gas hydrate nucleation. Chemical Engineering Science. 1994. 49: 2075-2087

Ning Z F, Zhang S X, Zhang Q, et al. Experimental and modeling study of kinetics for methane hydrate formation with tetrahydrofuran as promoter. Petroleum Science. 2007. 4(1): 61-65

Pauchard V, Darbouret M, Palermo T, et al. Gas hydrate slurry flow in a black oil. Prediction of gas hydrate particles agglomeration and linear pressure drop. 13th International Conference on Multiphase
Production Technology, Edinburgh, UK. June 13-15, 2007

Peng D Y and Robinson D B. A new two-constant equation of state. Industrial \& Engineering Chemistry, Fundamental. 1976. 15: 59-64

Skovoborg P, Ng H J, Rasmussen P, et al. Measurement of induction times for the formation of methane and ethane gas hydrate. Chemical Engineering Science. 1993. 48: 445-453

Sun C Y, Chen G J and Yue G L. The induction period of hydrate formation in a flow system. Chinese Journal of Chemical Engineering. 2004. 12(4): 527-531

Turner D J, Boxall J, Yang S, et al. Development of a hydrate kinetic model and its incorporation into the OLGA2000® transient multiphase flow simulator. Proceedings of the 5 th International Conference on Gas Hydrates, Trondheim, Norway, June 13-16, $2005 a$

Turner D J, Kleehammer D M, Miller K T, et al. Formation of Hydrate Obstructions in Pipelines: Hydrate Particle Development and Slurry Flow. Proceedings of the 5th International Conference on Gas Hydrates, Trondheim, Norway, June 13-16, 2005b

Wang W C, Fan S S and Liang D Q. Experimental study on flow characters of $\mathrm{CH}_{3} \mathrm{CCL}_{2} \mathrm{~F}$ hydrate slurry. International Journal of Refrigeration. 2007. 31: 371-378

Zhao J K, Gong J and Xia Q C. Study outlines method for managing unexpected liquid. Oil \& Gas Journal. 2009. 107(23): 52-55

(Edited by Sun Yanhua) 